\title{
Efeito dos Estrógenos Conjugados e da Medroxiprogesterona sobre a Mama: Estudo Experimental
}

\author{
Effect of Conjugated Estrogens and of Medroxyprogesterone on Breast \\ Tissue: an Experimental Study
}

Luciana de Oliveira Marques dos Santos, Maria de Lourdes Pessole Biondo-Simões Sérgio Ossamu Ioshii

\begin{abstract}
RESUM0
Objetivo: avaliar no tecido mamário a influência de drogas empregadas na terapia de reposição hormonal sobre a proliferação celular, a quantidade de colágeno e de fibras elásticas e as alterações histológicas gerais do parênquima.

Método: utilizaram-se 61 ratas Wistar-UFPR, adultas, divididas em 5 grupos. O grupo padrão $(n=12)$ representou o perfil hormonal ovariano normal. As 49 ratas restantes foram ooforectomizadas e a partir do $96^{\circ}$ dia P.O. receberam a medicação designada para cada grupo durante 30 dias. O grupo EEC ( $n=13)$ recebeu $50 \mathrm{mg} /$ dia de estrógenos eqüinos conjugados; o grupo MPA ( $n=12), 2,0 \mathrm{mg} /$ dia de acetato de medroxiprogesterona; o grupo EEC + MPA $(n=12)$, ambos, e o grupo $A D(n=12)$, água destilada. No $31^{\circ}$ dia de medicação todos os animais foram sacrificados e as mamas inguinais foram retiradas para análise histológica. A avaliação da proliferação celular nos ductos e ácinos foi realizada por método imuno-histoquimico utilizando-se anticorpo anti-PCNA. Utilizando-se a coloração de Sirius-Red quantificou-se o colágeno maduro (tipo I) e imaturo (tipo III). A coloração de Weigert avaliou a formação de fibras elásticas. A análise anatomopatológica foi realizada em coloração de hematoxilina-eosina, determinando-se o número de ácinos por ducto terminal, número de ductos por campo, presença de secreção intraductal e a intensidade de vacuolização intracitoplasmática.

Resultados: o grupo EEC + MPA apresentou menor porcentagem de células ductais em proliferação $(46,1 \%)(p<0,0001)$. Também mostrou maior taxa de proliferação das células acinares $(66,3 \%)$, sendo semelhante ao grupo MPA $(p=0,075)$ mas diferente dos demais grupos $(p<0,004)$. No grupo EEC encontrou-se maior quantidade de colágeno imaturo $(33,6 \%)(p<0,01)$ e o grupo MPA apresentou mais elevada concentração de fibras elásticas $(11,7 \%)(p<0,0001)$. Os grupos EEC + MPA e MPA apresentaram hiperplasia acinar secretora, sendo intensa (91,7\%) no grupo EEC + MPA e discreta $(41,7 \%)$ ou moderada $(58,3 \%)$ no grupo MPA, mas ambos diferentes dos demais grupos $(p<0,097)$.

Conclusões: os estrógenos eqüinos conjugados associados a acetato de medroxiprogesterona inibem a proliferação celular ductal e estimulam a proliferação celular acinar promovendo hiperplasia acinar secretora; os estrógenos eqüinos conjugados intensificam a formação de colágeno imaturo (tipo III) e o acetato de medroxiprogesterona aumenta a formação de fibras elásticas.
\end{abstract}

PALAVRAS-CHAVE: Terapia de reposição hormonal. Mama: câncer. Proliferação celular. Colágeno.

Instituto de Pesquisas Médicas da Faculdade Evangélica de Medicina do Paraná - Hospital Universitário Evangélico de Curitiba.

Correspondência: Luciana de Oliveira Marques dos Santos

Rua Gastão Câmara 694, ap. 1202 - Champagnat

80730-300 - Curitiba - PR

Pesquisa realizada com apoio financeiro do $\mathrm{CNPq}$
Introdução

Uma meta-análise, envolvendo mais de 51 estudos provenientes da América do Norte e Europa, mostrou que o risco de câncer de mama está 
aumentado em mulheres sob terapia de reposição hormonal (TRH) e que este risco é maior quanto mais prolongado for tal uso (Collaborative Group on Hormonal Factors in Breast Cancer) ${ }^{1}$. Outra metaanálise, avaliando o uso combinado de estrogênio e progesterona, concluiu que a progesterona não reduz o risco de câncer de mama ${ }^{2}$. Ainda outros autores, avaliando a ação dos progestágenos na pós-menopausa, sugeriram existir aumento do risco de câncer de mama em mulheres idosas que usam estes hormônios ${ }^{3}$.

Sabendo que o epitélio mamário na pós-menopausa é hormônio-dependente e responde às mudanças dos niveis séricos de hormônios esteróides $^{4}$, e que o estrogênio promove proliferação celular, induz a formação de receptores e aumenta a sintese de DNA das células do estroma e do epitélio ${ }^{5}$, supõe-se que o risco de câncer de mama seria menor em mulheres com reduzido tempo de exposição ao estradiol, devido a uma menor proliferação celular mamária ${ }^{4}$.

Está bem estabelecido o efeito mitogênico dos estrógenos sobre as células epiteliais da mama $^{6}$, mas o efeito dos progestágenos é considerado controverso ${ }^{3}$, podendo tanto inibir quanto estimular a proliferação celular ${ }^{6}$, restando por isto a dúvida de qual seria o melhor esquema de TRH para mulheres sem útero ${ }^{3}$.

Lembrando que o aumento da proliferação de células epiteliais normais associado à perda do controle de regulação desta proliferação é o marco principal do câncer, deve-se ter muito critério ao se prescrever TRH.

Em tecidos responsivos aos estrógenos, incluindo epitélio mamário normal e neoplásico, a regulação da proliferação pelos esteróides e pelos antagonistas dos esteróides ocorre por ação específica sobre as células na fase $G_{1}$ do ciclo celular ${ }^{7}$. Este então seria o alvo de estudo da proliferação celular.

Dentre os métodos de avaliação da proliferação celular, pode-se empregar entre outros $o$ índice de mitose ou o método imuno-histoquímico utilizando anticorpo anti-PCNA (proliferating cell nuclear antigen), pois ambos apresentam uma boa correlação entre $\mathrm{si}^{8}$. O método imuno-histoquímico é um marcador seguro da proliferação celular mamária em tecidos não-neoplásicos, uma vez que identifica todas as células em multiplicação da fase $G_{1}$ até a fase $M$ do ciclo celular ${ }^{8}$.

Além do epitélio devemos considerar o estroma das mamas, no qual altas doses de estrógenos administrados por tempo prolongado podem provocar um aumento do tecido conjuntivo intralobular e periductal ${ }^{9}$.

Isto posto, muito ainda é necessário até se obter um consenso sobre TRH e risco de câncer de mama, pois o efeito dos hormônios esteróides sobre o tecido mamário é complexo, envolvendo, além da proliferação celular, a morte celular programada e a expressão de receptores celulares.

Assim, os objetivos desta pesquisa são avaliar no tecido mamário sob TRH a proliferação celular, a quantidade de colágeno maduro e imaturo, a quantidade de fibras elásticas e as alterações histológicas gerais do parênquima.

\section{Material e Métodos}

Foram utilizados 61 ratos Rattus norvegicus albinus, Rodentia, Mammalia, Wistar-UFPR, fêmeas virgens, com idade média de 202 dias e peso inicial médio de 201,45 gramas.

Os animais foram alojados em grupos de 6 ou 7 por caixa, no Biotério da Faculdade Evangélica de Medicina do Paraná, onde o ciclo claro/escuro e a umidade eram os do ambiente geral. A temperatura ambiente era mantida constante $\left(24^{\circ} \mathrm{C}\right)$ e as gaiolas estavam colocadas todas à mesma distância do solo. As ratas recebiam água e ração padrão comercial à vontade.

A amostra foi dividida aleatoriamente em 5 grupos, conforme o tratamento proposto: grupo padrão com 12 ratas não-ooforectomizadas; grupo $\mathrm{AD}$ com 12 ratas ooforectomizadas, que receberam 1 $\mathrm{mL} /$ dia de água destilada; grupo EEC com 13 ratas ooforectomizadas, que receberam 50,0 $\mu \mathrm{g} /$ dia de estrogênios eqüinos conjugados; grupo MPA com 12 ratas ooforectomizadas, que receberam $2,0 \mathrm{mg} /$ dia de acetato de medroxiprogesterona, e grupo EEC + MPA com 12 ratas ooforectomizadas, que receberam $50,0 \mathrm{mg} /$ dia de estrogênios eqüinos conjugados associado a $2,0 \mathrm{mg} /$ dia de acetato de medroxiprogesterona. Os animais foram pesados no primeiro dia do experimento (peso inicial), no primeiro dia de administração da medicação (peso intermediário) e no dia do sacrificio (peso final), para posterior avaliação da variação ponderal. Procedeu-se à anestesia inalatória com éter etílico para pesagem, bem como para todos os procedimentos dolorosos realizados.

No primeiro dia do experimento o grupo padrão foi sacrificado com dose letal inalatória de éter etílico, sendo realizada depilação ventral e ressecção das quatro mamas inguinais, por meio de incisão cutânea de $1,0 \times 1,0 \mathrm{~cm}$; essas mamas serviram como padrão histológico de normalidade do parênquima mamário. Nos 49 animais restantes procedeu-se à ooforectomia bilateral.

No $96^{\circ}$ dia pós-operatório, depois de pesados (peso intermediário), iniciou-se a administração da medicação designada a cada grupo. Utilizou-se 
como veículo da medicação 1,0 mL de água destilada, sendo esta administrada por gavagem, diariamente no mesmo horário, durante 30 dias consecutivos.

No $31^{\circ}$ dia depois de iniciada a medicação, estes 49 animais foram novamente pesados (peso final), sacrificados e submetidos a exérese das mamas inguinais da mesma forma que a realizada no grupo padrão.

A última mama inguinal esquerda foi fixada em formalina tamponada por 24 horas e logo após incluída em parafina. Esta mama foi destinada à análise imuno-histoquímica de proliferação celular pelo método de imunoperoxidaseestreptavidina-biotina, para identificação do PCNA. As demais mamas foram fixadas em formalina a $10 \%$, sendo que na penúltima mama inguinal esquerda realizou-se a técnica de coloração do SiriusRed, preconizada por Junqueira et al. ${ }^{10}$ para quantificação de fibras colágenas maduras (tipo I) e imaturas (tipo III). Na última mama inguinal direita quantificaram-se as fibras elásticas por meio da técnica de coloração de Weigert e na penúltima mama inguinal direita utilizou-se a técnica de coloração de hematoxilina-eosina para análise anatomopatológica do parênquima em geral.

Para realização da técnica imunohistoquímica utilizou-se como anticorpo primário o anti-PCNA clone PC-10 (Dako) na diluição 1/7000 com incubação de 18 horas a $-4^{\circ} \mathrm{C}$, e como anticorpo secundário o Biotinilado-LSAB-2 (Dako) com incubação de 1 hora a $37^{\circ} \mathrm{C}$. A amplificação foi realizada pelo método LSAB (Dako) por 30 minutos a $37^{\circ} \mathrm{C}$, utilizando-se a enzima peroxidase. Ao final da técnica usou-se o cromógeno DAB por 5 minutos $^{11} \mathrm{e} \mathrm{a}$ contracoloração de hematoxilina de Harrys.

$\mathrm{Na}$ análise imuno-histoquímica foram quantificados os núcleos celulares corados em azul, os quais representam células em repouso, e os núcleos corados em marrom, que identificam as células em proliferação. Tal análise foi realizada separadamente nas células dos ductos e dos ácinos mamários. O número de células em proliferação e repouso nos ductos foi quantificado em 5 campos do corte histológico, com aumento de 400 vezes. A seguir calculava-se a média de núcleos azuis e marrons nos 5 campos para cada corte histológico e convertia-se o valor absoluto em porcentagem. Na análise das células dos ácinos, foram observados 3 campos do corte histológico. Quanto aos demais aspectos empregamos os mesmos critérios quando da análise das células dos ductos.

As fibras colágenas e elásticas foram quantificadas por meio de captação de imagem com microscópio óptico da marca Olimpus ${ }^{\circledR}$, modelo DX50, em aumento de 200 vezes, utilizando-se fil- tro polarizador. As imagens captadas por uma câmara Sony Trinitron CCD $101^{\circledR}$ colorida foram congeladas e digitalizadas por meio de placas Oculus $\mathrm{TCX}^{\circledR}$ e transformadas em linguagem binária pelo aplicativo Optimas 6.0 for Windows do Bioscan Incorporated Institute ${ }^{\circledR}$.

Para análise de fibras colágenas procediase à captação de imagem em 4 campos, e em cada campo eram quantificadas as fibras coradas em verde, que representam fibras colágenas imaturas (tipo III), e as fibras coradas em vermelho, que denotam as fibras colágenas maduras (tipo $\mathrm{I}^{10}$. Calculou-se a média e o valor absoluto foi convertido em porcentagem de fibras verdes e vermelhas, nos 4 campos estudados.

As fibras elásticas foram avaliadas como as fibras colágenas, porém estas foram quantificadas mediante captação de imagem com microscópio óptico de luz polarizada calibrada para cor azul, pois as mesmas coram-se em azul pela técnica utilizada.

Para análise anatomopatológica das mamas consideraram-se o número de ácinos mamários por ducto terminal, o número de ductos em quatro campos do corte histológico sob aumento panorâmico, a intensidade de vacuolização intracitoplasmática e a presença de secreção intraductal. O número de ductos por campo e o número de ácinos por ducto terminal foram comparados ao grupo padrão e classificados em normal, atrofia e hiperplasia, sendo normal quando igual ao observado no grupo padrão, atrofia quando menor e hiperplasia quando maior que o encontrado no grupo padrão. A hiperplasia foi quantificada subjetivamente em discreta (Figura 1), moderada e intensa (Figura 2), segundo a intensidade de aumento de ductos ou ácinos ${ }^{12-14}$. Quando observada secreção intraductal e vacuolização intracitoplasmática, associada à hiperplasia, esta foi designada como hiperplasia secretora.

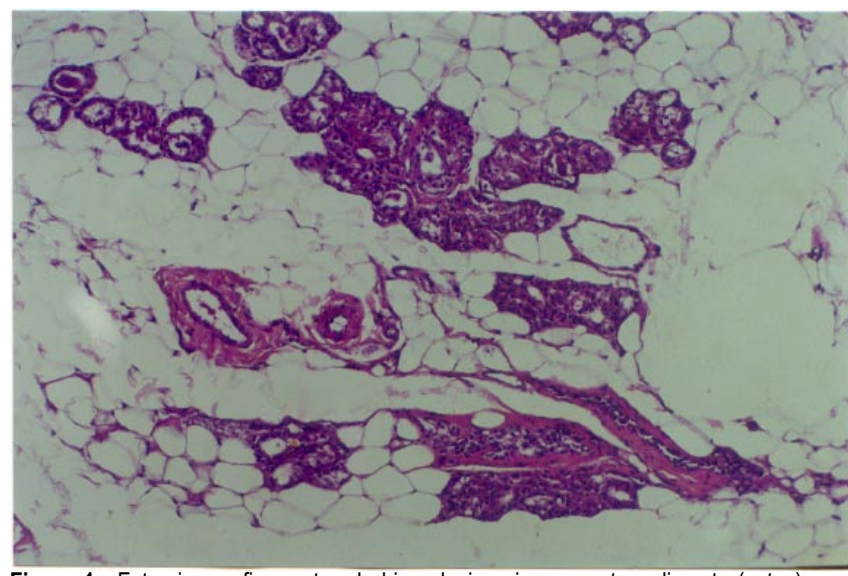

Figura 1 - Fotomicrografia mostrando hiperplasia acinar secretora discreta (setas), em corte histológico de mama de animal que recebeu acetato de medroxiprogesterona (HE,X100). 


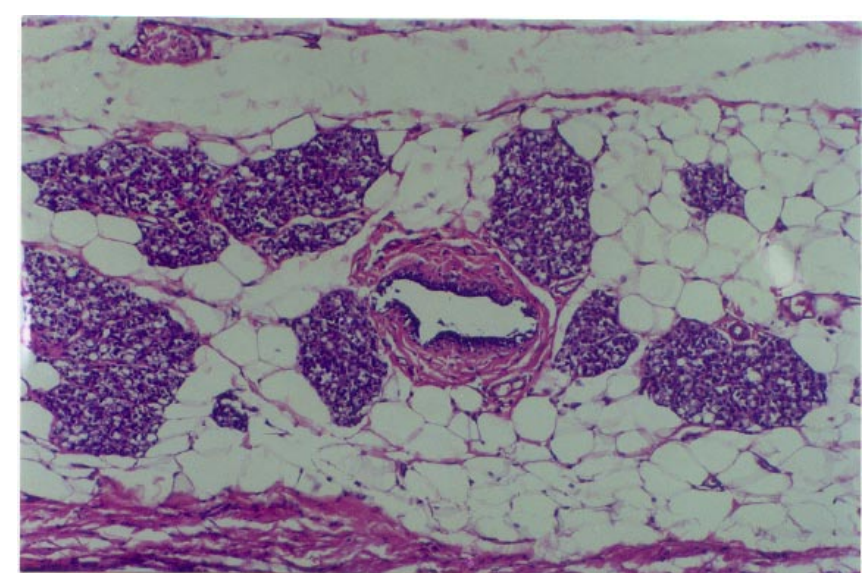

Figura 2 - Fotomicrografia mostrando hiperplasia acinar secretora intensa (setas), em corte histológico de mama de animal que recebeu a associação de estrógenos conjugados e acetato de medroxiprogesterona (HE,X100).

Para comparação dos dados levantados, utilizou-se a análise de variância (ANOVA). Na análise estatística da proliferação celular, quantificação de fibras colágenas e elásticas, utilizaramse os testes paramétricos $t$ de Student e os nãoparamétricos de Mann-Whitney (por meio do software "Primer of Biostatistics") ${ }^{15}$. A análise estatística das alterações anatomopatológicas foi realizada pelo teste do $\chi^{2}$ com correção de Yates e teste exato de Fisher (pelo software Epi-Info) para amostras independentes ${ }^{16}$. Utilizou-se ainda o teste paramétrico $t$ de Student pareado, para comparação do peso dos animais nas diferentes fases do estudo. Em todos os testes fixou-se em 5,0\% o nível de rejeição da hipótese de nulidade, sendo nas figuras indicados com asteriscos os resultados significantes.

\section{Resultados}

Realizando-se análise comparativa intragrupo para as três aferições de peso do animal, constatou-se diferença significante em todas as comparações $(\mathrm{p}<0,01)$, observando-se em todos os grupos aumento de peso da fase inicial para a intermediária (grupo AD 35,8\%, grupo EEC $26,0 \%$, grupo MPA 25,6\% e grupo EEC + MPA 19,6\%) e perda de peso da fase intermediária para a final (grupo AD -5,4\%, grupo EEC - $7,8 \%$, grupo MPA $-3,6 \%$ e grupo EEC + MPA $-5,7 \%$ ).

$\mathrm{Na}$ análise dos ductos mamários, observouse a menor porcentagem de células em proliferação no grupo EEC + MPA (46,1\%), sendo esta diferença significante $(p<0,0001)$ em comparação com os grupos AD, EEC e MPA. A maior porcentagem de células ductais em proliferação ocorreu no grupo padrão $(59,0 \%)$, sendo esta diferença também significante $(p<0,01)$ quando comparada aos outros quatro grupos (Figura 3).

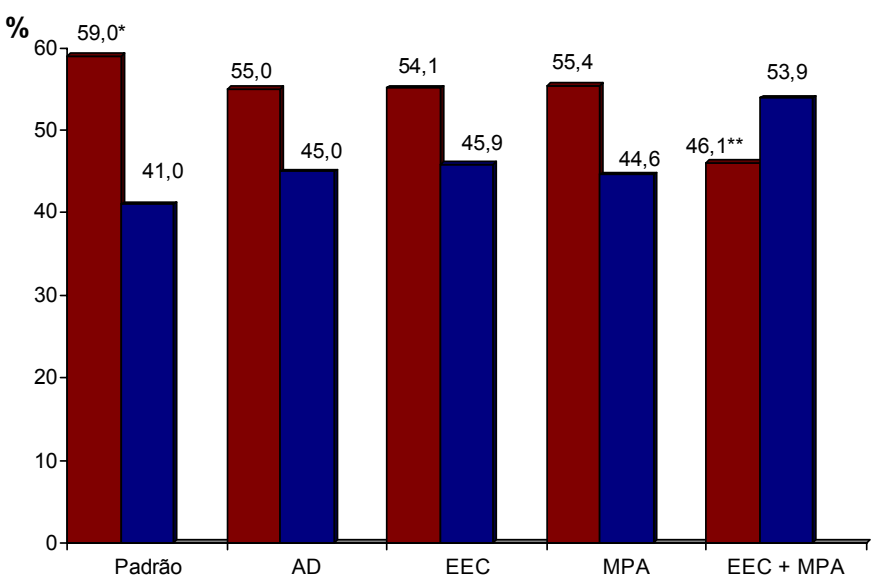

Grupo padrão

Grupo $A D=$ água destilada

Grupo EEC = estrógenos equinos conjugados

Grupo MPA = acetato de medroxiprogesterona

Grupo EEC + MPA = estrógenos equinos conjugados e acetato de medroxiprogesterona

Figura 3 - Porcentagem de células em fase de proliferação (marrom) e de células em repouso (azul), nos ductos mamários de cada grupo, segundo a análise imunohistoquímica com anticorpo anti-PCNA $\left({ }^{*} p<0,01,{ }^{* *} p<0,001\right)$.

Em relação aos ácinos mamários, encontrou-se no grupo EEC + MPA a maior porcentagem de células em fase de proliferação $(66,3 \%)$, tendo diferença significante $(p<0,004)$ quando comparado aos grupos padrão, AD e EEC, mas sem diferença em relação ao grupo MPA $(p=0,075)$ (Figura 4).

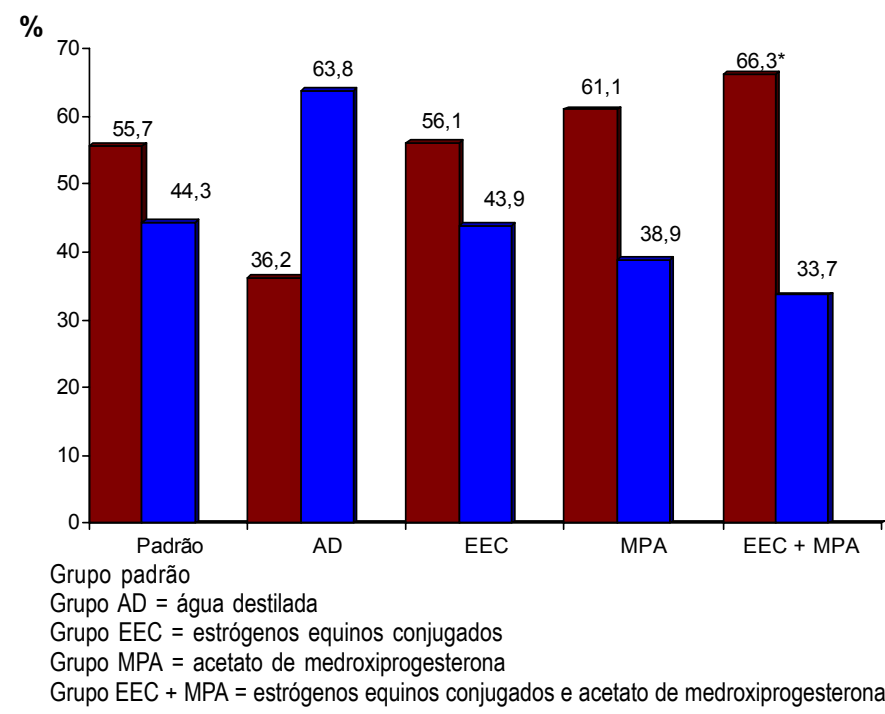

Figura 4 - Porcentagem de células em fase de proliferação (marrom) e de células em repouso (azul), nos ácinos mamários de cada grupo, segundo a análise imunohistoquímica com anticorpo anti-PCNA $\left({ }^{*} p<0,004\right)$.

Considerando-se as porcentagens de colágeno maduro (tipo I) e imaturo (tipo III), en- 
controu-se no grupo EEC o menor valor de colágeno maduro $(66,4 \%)$ e o maior valor de colágeno imaturo $(33,6 \%)$, sendo estes significantes $(p<0,01)$. Os demais grupos foram semelhantes entre si, em relação à quantidade de colágenos (Figura 5).

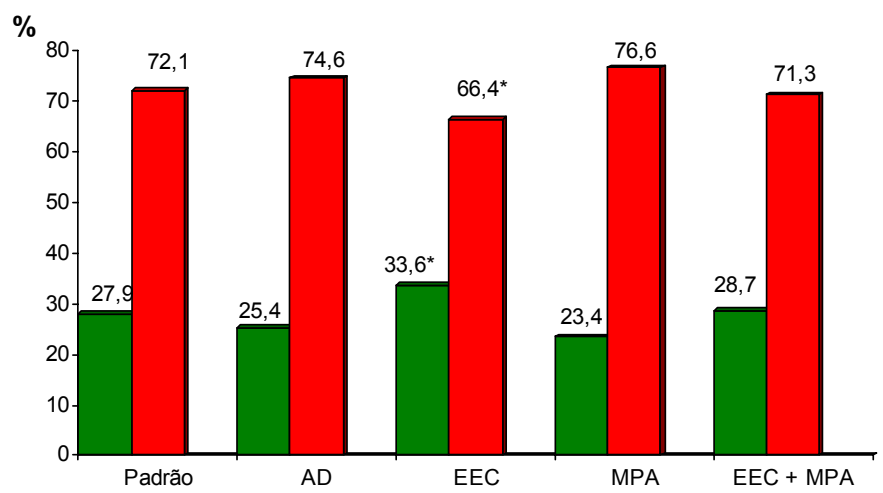

Grupo padrão

Grupo $A D$ = áqua destilada

Grupo EEC = estrógenos equinos conjugados

Grupo MPA = acetato de medroxiprogesterona

Grupo EEC + MPA = estrógenos equinos conjugados e acetato de medroxiprogesterona

Figura 5 - Porcentagem de colágeno imaturo (verde) e maduro (vermelho) em cada grupo segundo a coloração de Sirius-Red $\left({ }^{*} p<0,01\right)$.

Observaram-se fibras elásticas tanto ao redor dos ductos quanto ao redor dos grupamentos acinares e no estroma da glândula mamária, embora pudessem ser vistas, subjetivamente, em maior concentração ao redor dos ductos, em todos os grupos.

Quanto à quantidade de fibras elásticas, os grupos padrão e AD mostraram-se semelhantes entre si $(p=0,627)$ e apresentaram as menores porcentagens destas fibras $(7,0 \%$ e $6,7 \%$, respectivamente). Os grupos EEC, MPA e EEC + MPA foram significativamente diferentes $(p<0,0001)$ dos grupos padrão e $\mathrm{AD}$, apresentando as maiores porcentagens de fibras elásticas $(10,4 \%, 11,7 \%$ e $10,9 \%$, respectivamente), sendo esta diferença mais evidente no grupo MPA.

Por meio da avaliação anatomopatológica, observou-se que os hormônios utilizados não demonstraram influência sobre os ductos mamários, em nenhum grupo de estudo. Contudo, seus efeitos foram observados sobre os ácinos mamários, sobretudo no grupo EEC + MPA, em que 91,7\% dos animais apresentaram hiperplasia acinar secretora intensa. A mesma hiperplasia acinar secretora foi observada no grupo MPA, porém de menor intensidade, sendo discreta em $41,7 \%$ e moderada em $58,3 \%$ dos animais.

Quando comparado o grupo EEC + MPA com os grupos padrão, AD e EEC verificou-se que a diferença quanto à frequência de hiperplasia acinar secretora foi significante $(p=0,0002, p=0,0023 \mathrm{e}$ $\mathrm{p}=0,0097$, respectivamente).

\section{Discussão}

Permanecem contraditórios os efeitos do estrogênio e de sua associação com progesterona, sobre o parênquima mamário. Bässler ${ }^{17}$, MauvaisJarvis et al. ${ }^{18}$ e Chang et al. ${ }^{8}$ afirmam que o estradiol estimula o crescimento ductal, contudo Silva et al. ${ }^{14}$, relatam que os estrogênios produzem atrofia do epitélio mamário. Colditz et al. ${ }^{3}$ citam que a adição de progesterona à terapia de reposição estrogênica não reduz o risco de câncer de mama, baseando-se em evidências de que esta associação poderia aumentar a proliferação celular epitelial da mama. Já Hargreaves et al. ${ }^{4}$ não observaram diferenças com relação à proliferação celular mamária quando utilizado estrógeno ou estrógeno associado a progesterona.

Nas condições estudadas, a associação de estrogênios conjugados e acetato de medroxiprogesterona diminuiu a proliferação de células ductais mamárias, sendo que a maior taxa de proliferação destas células foi observada nos animais que estavam sob influência dos hormônios ovarianos endógenos. Isto sugere que a variação hormonal do ciclo sexual provocaria um maior estímulo sobre a proliferação celular ductal. Achados similares foram encontrados por MauvaisJarvis et al. ${ }^{18}$ : o estradiol e a progesterona, secretados numa proporção adequada, permitiram um desenvolvimento peculiar e completo da glândula mamária.

No presente experimento, a castração acarretou diminuição da taxa de proliferação de células acinares, sugerindo que a falência hormonal da menopausa seria um fator benéfico em relação ao risco de câncer de mama, achados estes condizentes com os de Pike et al. ${ }^{19}$. Ainda, a administração isolada de acetato de medroxiprogesterona, bem como sua associação com estrogênios conjugados, induziu maior proliferação de células acinares. Os mesmos achados foram relatados por Bässler ${ }^{17}$, que observou que a progesterona estimulou a lobulação e formação de ácinos e a combinação de progesterona e estrógenos provocou diferenciação lóbulo-alveolar em ratas.

Mauvais-Jarvis et al. ${ }^{9}$ verificaram que o estradiol provocou um aumento do tecido conjuntivo intralobular da mama de ratas castradas sob efeito estrogênico prolongado. Achados similares foram observados por Vogel et al. ${ }^{20}$, com tecido conjuntivo mais denso na fase folicular do ciclo menstrual da mulher. Neste estudo os estrógenos conjugados estimularam a formação de colágeno imaturo (tipo III), ou seja, colágeno novo, o que aumentaria a densidade do parênquima mamário possivelmente dificultando a avaliação mamográ- 
fica de lesões iniciais da mama.

Raafat et al. ${ }^{21}$ relatam maior síntese de DNA nas células estromais circundando ductos terminais, e ainda maior resposta proliferativa das células do estroma simultaneamente à das células epiteliais, indicando que existe uma interação parácrina entre o epitélio dos ductos e o estroma próximo.

No presente experimento, o acetato de medroxiprogesterona e estrógenos conjugados estimularam a formação de fibras elásticas no parênquima mamário, sendo maior o estímulo quando empregado o acetato de medroxiprogesterona isoladamente.

Ainda, o acetato de medroxiprogesterona, isolado ou associado a estrógenos conjugados, provocou hiperplasia acinar secretora, sendo que quando isolado o fez de forma discreta ou moderada e quando associado, de forma intensa. Isto demonstra que, nos ácinos, os estrógenos conjugados potencializam o efeito do acetato de medroxiprogesterona, talvez porque os estrógenos aumentem o nivel de receptores de progesterona na célula-alvo, aumentando sua responsividade tecidual à progesterona, como já relatado por Colditz et al. ${ }^{3}$ e Stanford \& Thomas $^{22}$. Estas observações assemelham-se às encontradas na análise imunohistoquímica deste estudo, no qual a progesterona associada a estrógenos aumentou a proliferação de células acinares.

Apesar de existirem diferenças entre a mama humana e a da rata, o modelo de estudo em ratas pode ser considerado adequado para entender a doença mamária em humanos, como anteriormente citado por Russo et al. ${ }^{23}$.

Concluimos que a associação estrógenos eqüinos conjugados e acetato de medroxiprogesterona inibe a proliferação celular ductal e estimula a proliferação celular acinar, promovendo hiperplasia acinar secretora. Concluiu-se também que os estrógenos eqüinos conjugados intensificam a formação de colágeno imaturo (tipo III) e que o acetato de medroxiprogesterona aumenta a formação de fibras elásticas.

\section{SUMMARY}

Purpose: to evaluate the effect of hormone replacement therapy on breast cell proliferation and on collagen and elastic fiber formation and to analyze the changes occurring in the breast parenchyma as a whole.

Method: a total of 61 adult Wistar rats were divided into 5 groups. The standard group (12 rats) represented the normal hormonal ovarian status. The remaining 49 rats were oophorectomized and, starting on the 96th P.O. day, received the specific drug for 30 days. The CEE group received $50 \mathrm{mg} /$ day conjugated equine estrogens (13 rats); the MPA group, $2.0 \mathrm{mg} /$ day medroxyprogesterone acetate (12 rats); the CEE + MPA group, both drugs (12 rats), and the DW group, distilled water (12 rats). On the 31st day of medication, the animals were sacrificed and the inguinal mammary glands were removed for histological analysis. Cell proliferation was assessed at the ductal and acinar levels using anti-PCNA antibody. Mature collagen (type I) and immature collagen (type III) were quantified by Sirius-Red staining, and elastic fiber formation was quantified by Weigert staining. Anatomopathological analysis was performed by hematoxylin-eosin staining, with the determination of number of acini per terminal duct, number of ducts per field, presence of intraductal secretion, and intensity of intracytoplasmic vacuolization.

Results: the CEE + MPA group presented a smaller percentage of proliferating ductal cells $(46.1 \%)(p<0.0001)$ and a greater proliferation of acinar cells (66.3\%), similar to those detected in the MPA group ( $p=0.075)$ but differing from those detected in the remaining groups $(p<0.004)$. The CEE group showed the largest amount of immature collagen (33.6\%) $(p<0.01)$ and the MPA group showed the highest concentration of elastic fibers $(11.7 \%)(p<0.0001)$. The CEE + MPA and MPA groups showed secretory acinar hyperplasia that was intense (91.7\%) in the CEE + MPA group and mild (41.7\%) or moderate (58.3\%) in the MPA group, but differering in both cases from the remaining groups $(p<0,097)$.

Conclusions: conjugated equine estrogens in combination with medroxyprogesterone inhibit ductal cell proliferation and stimulate acinar cell proliferation causing secretory acinar hyperplasia; conjugated horse estrogens intensify the formation of immature (type III) collagen, and medroxyprogesterone acetate increases the formation of elastic fibers.

KEY WORDS: Hormonal replacement therapy. Breast: neoplasm. Cell proliferation. Collagen.

\section{Referências}

1. Breast cancer and hormone replacement therapy: collaborative reanalysis of data from 51 epidemiological studies of 52705 women with breast cancer and 108411 women without breast cancer. Collaborative Group on Hormonal Factors in Breast Cancer. Lancet 1997; 50:1047-59.

2. Colditz GA, Egan KM, Stampfer MJ. Hormone replacement therapy and risk of breast cancer: results from epidemiologic studies. Am J Obstet Gynecol 1993; 168:1473-80.

3. Colditz GA, Hankinson SE, Hunter DJ, et al. The use of estrogens and progestins and the risk of breast cancer in postmenopausal women. N Engl J Med 1995; 332:1589-93. 
4. Hargreaves DF, Knox F, Swindell R, Potten CS, Bundred NJ Epithelial proliferation and hormone receptor status in the normal post-menopausal breast and the effects of hormone replacement therapy. Br J Cancer 1998; 78:945-9.

5. Andrade PM. Aspectos histomorfométricos do endométrio de ratas adultas castradas após o uso de estrogênio, progestogênio e tamoxifeno [dissertação]. São Paulo: Escola Paulista de Medicina; 1999.

6. Söderqvist G. Effects of sex steroids on proliferation in normal mammary tissue. Ann Med 1998; 30:511-24.

7. Sutherland RL, Hamilton JA, Sweeney KJ, Watts CK, Musgrove EA. Expression and regulation of cyclin genes in breast cancer. Acta Oncol 1995; 34:651-6.

8. Chang KJ, Lee TT, Linares-Cruz G, Fournier S, de Ligniéres B. Influences of percutaneous administration of estradiol and progesterone on human breast epithelial cell cycle in vivo. Fertil Steril 1995; 63:785-91.

9. Mauvais-Jarvis P, Kuttenn F, Gompel A. Antiestrogen action of progesterone in breast tissue. Breast Cancer Res Treat 1986; 8:179-88.

10.Junqueira LCU, Bignolas G, Brentani RR. A simple and sensitive method for the quantitative estimation of collagen. Anal Biochem 1979; 94:96-9.

11.Hsu SM, Raine L, Fanger H. Uso of avidin-biotinperoxidase complex $(\mathrm{ABC})$ in immunoperoxidase techniques: a comparison between $\mathrm{ABC}$ and unlabeled antibody (PAP) procedures. J Histochem Cytochem 1981; 29:577-80.

12.Anderson TJ, Page, DL. The breast. In: McGee JOD, Issacson PG, Wright NA, editors. Oxford Textbook of Pathology. 1st ed. Oxford: Oxford University Press; 1992. p.1643-63.

13.Rosai J. Breast. In: Rosai J, editor. Ackerman's Surgical Pathology. 1st ed. New York: Mosby Year Book; 1996. p.1565-660.
14. Silva BB, Gebrim LH, Simões MJ, Baracat EC, Lima GR. Efeitos do tamoxifeno e dos estrogênios conjugados no epitélio mamário de ratas em estro permanente. Rev Bras Ginecol Obstet 2000; 22:33-6.

15.Glantz SA. Primer of biostatistics [computer program]. Version 4.0. 4th ed. New York; 1997.

16.World Health Organization. Centers for Disease Control \& Prevention (CDC) [computer program]. Version 6.04b. Genebra: A Word Processing, Database and Statistics Program for Public Health; 1997.

17.Bässler R. The morphology of hormone induced structural changes in the female breast. Curr Top Pathol 1970; 53:1-89.

18.Mauvais-Jarvis P, Kuttenn F, Gompel A. Estradiol/ progesterone interaction in normal and pathologic breast cells. Ann N Y Acad Sci 1986; 464:152-67.

19.Pike MC, Spicer DV, Dahmoush L, Press MF. Estrogens, progestogens, normal breast cell proliferation, and breast cancer risk. Epidemiol Rev 1993; 15:17-35.

20.Vogel PM, Georgiade NG, Fetter BF, Vogel FS, McCarty $\mathrm{K} \mathrm{Jr}$. The correlation of histologic changes in the human breast with the menstrual cycle. Am J Pathol 1981; 104:23-34.

21.Raafat AM, Hofseth LJ, Li S, Bennett JM, Haslam SZ. A mouse model to study the effects of hormone replacement therapy on normal mammary gland during menopause: enhanced proliferative response to estrogen in late postmenopausal mice. Endocrinology 1999; 140:2570-80.

22.Stanford JL, Thomas DB. Exogenous progestins and breast cancer. Epidemiol Rev 1993; 15:98-107.

23.Russo J, Gusterson BA, Rogers AE, Russo IH, Wellings SR, van Zwieten MJ. Comparative study of human and rat mammary tumorigenesis. Lab Invest 1990; 62:244-78. 